\title{
Stigma in the Social Life among Mothers Having Children with Intellectual Disabilities: Challenges and Suggestions
}

\author{
Rajesh Kumar Mourya ${ }^{1 *}$, R. N. Singh ${ }^{2}$, Ashok Rai ${ }^{3}$
}

\section{ABSTRACT}

This study examined the role of severity of children's intellectual disability and perceived stigma in restriction in social life among the parents of such children .The correlational research design was used for this purpose. The sample for the study consisted of fifty one mother having intellectually disabled children of varying degree, aged between 3 to 15 years. The participants were sampled from different rehabilitation centers and special schools at Varanasi. They were administered Personal Care Assessment Form, Perceived Stigma Scale and Restriction of Social Life Scale. Correlation analysis was applied to see the relationship which revealed that the child's activity limitation is significantly positively associated with stigma and restriction in social life. Stigma was also significantly positively associated with restricted social life. This paper highlights the growing need for interventions that include both behavioral and psychosocial components to better address needs of families of children with intellectual disability. It is concluded that there exists a need for future research on culturally sensitive parent training as well as on potentially efficient group-based parent education programs for families of children with moderate to profound intellectual disability.

Keywords: Stigma, social life \& Mother of children with ID

The term intellectual disability (ID) is increasingly being used instead of mental retardation. Mental retardation is defined as a condition of arrested or incomplete development of the mind, which is especially characterized by impairment of skills manifested during the developmental period, which contribute to the overall level of intelligence, i.e., cognitive, language, motor, and social abilities (WHO, 1992). The American Association on Intellectual and Developmental Disabilities (AAIDD) describes ID as characterized by significant limitations both in intellectual functioning and in adaptive behavior as expressed in conceptual, social, and practical adaptive

\footnotetext{
${ }^{1}$ Research scholar, Department of Psychology, BHU, Varanasi, India

${ }^{2}$ Professor, Department of Psychology, Banaras Hindu University, Varanasi, India

${ }^{3}$ Consultant Neonatologist \& Developmental Neurologist, Sai Hospital \& Secretly, Indian Institute of Cerebral Palsy and Handicapped Children (IICP), Varanasi, India)

*Responding Author

(C) 2016 I R Mourya, R Singh, A Rai; licensee IJIP. This is an Open Access Research distributed under the terms of the Creative Commons Attribution License (http://creativecommons.org/licenses/by/2.0), which permits unrestricted use, distribution, and reproduction in any Medium, provided the original work is properly cited.
} 


\section{Stigma in the Social Life among Mothers Having Children with Intellectual Disabilities: Challenges and Suggestions}

skills. This disability originates before age 18. In general, ID applies to the same individuals who were previously diagnosed with mental retardation in kind, level, type, duration and the need for services and supports. Every individual who is or was eligible for a diagnosis of mental retardation is eligible for a diagnosis of ID (Schalock, Luckasson \& Shogren, 2007).The impact of mental retardation is not only on the affected individuals but also on the family members, especially the parents, as they face a lot of challenges in caring of such children.

Challenges for the parents and families: The parents and families having ID children face a number of challenges which certainly interferes with functioning and social life.

Self-blame - The parents wonder if they did something wrong, during the course of the pregnancy or after birth, while taking care of the child. They wonder if God is punishing them for their sins.

Stigma- Many parents might feel that a intellectually disabled child is something to be ashamed of and cannot be allowed out of the house. Neighbors, relatives or others might make cruel remarks about the child and parents might feel isolated and without support.

Helplessness- Many parents don't know how to get help for their child once he/she has been diagnosed with I.D. The sense of helplessness comes both from a lack of understanding and scarce resources. It might be further aggravated by the unprofessional handling by the experts.

Behavior problems- Many parents find it difficult to handle behavioral problems like screaming, crying, inability to concentrate, aggressiveness, stubbornness etc. that a child with I.D might have, which may become wearisome. Often, the child might not understand how disruptive his/her behavior is to others and why they get angry.

Unrealistic expectations- Many times, parents of mentally retarded children are dissatisfied with the slow progress of their child is making in learning new things. These unrealistic expectations of what their child can achieve, it leads to disappointment not only for them, but also in the child who does not understand what he/she is doing wrong.

Worry about the future- One of the main concerns of parents with mentally retarded children is about how their children will be taken care of when they die. They feel that no one else can take care of their children with same love and care that they have and they are scared about how their child will manage to survive in the world.

Marital problems- Due to the extra tasks that have to be done to take care of the child, parents feel overworked, stressed out and unhappy. The marital relationship can become strained if the parents have diverse approaches in dealing with the child or if one parent has to take care of the child all the time.

All of these challenges are faced by the children and their families, specifically mothers but the most challenging part is stigma, it affects personal, emotional, social and psychological aspect of life. So the presented study is centralized to focus on the stigma of mothers and their children with intellectual disability. 


\section{Stigma in the Social Life among Mothers Having Children with Intellectual Disabilities: Challenges and Suggestions}

\section{Stigma}

The term 'stigma' is used to refer to a mark of social disgrace. Its roots lie in ancient Greece, where stizein was a physical mark placed on slaves in order for the public to identify their position and social standing, as indicative of their lower social value. One of the earliest definitions of stigma was offered by Goffman (1963) who described it as an "attribute that is deeply discrediting" reducing the bearer "from a whole and usual person to a tainted, discounted one', Several theorists and researchers have further conceptualized stigma and its dimensions. Social psychologists have defined stigma as comprised of cognitive, emotional, and behavioral aspects known as stereotypes, prejudice, and discrimination. The negative attitudes and stereotypes about a discredited subgroup lead to prejudice and discrimination toward such subgroups (Corrigan, 2000; Corrigan \& Watson, 2002). One way to approach understanding stigma is to see it as negative attitudes. In developing a public health oriented model of the process of stigma, Sartorius (1999) suggests that stigma is a cycle of disadvantage. It begins with the condition which manifests into a disability or impairment within society, such that stigma gets linked to the condition as an impairment. This leads to discrimination which can reduce an individual's ability and opportunity for rehabilitation. In turn, such barriers can create a malfunction in the individual's social role, such that the condition and its impairment are more pronounced and the cycle starts again. The public health perspective on stigma is based on an ecological view that includes both individual-level cognitive and emotional determinants, as well as the broader psycho-social and political determinants of stigma. Stigma affects not only individuals who carry the stigmatizing label, but also others who regularly associate with them (Ostman \& Kjellin, 2002; Goffman, 1963). For individuals with an intellectual disability, social support most of ten comes from family members who are active participants in their lives and who may themselves become targets for stigma (Phelan, Bromet\& Link, 1998; Struening, Perlick, Link, Hellman, Herman, \& Sirey, 2001). Disability is often associated with stigma and discrimination. The child's lack of abilities, unique needs and special treatment makes him as well as his family prone to social discrimination because the misconceptions and ignorance related to the disability.

\section{Stigma and children/individuals with ID}

Public stigma toward individuals with ID can take several forms. Individuals with ID may be exposed to teasing and stares, and may be avoided by others (Pratt, 2010). Discrimination toward individuals with ID is evidenced through the lack of decent services and discriminatory action within hospitals, such as lack of privacy and an overly restrictive environment (Jahoda \& Markova, 2004). Abraham, Gregory, Wolf,. \& Pemberton, (2002) reported that some persons with an intellectual disability are also aware that they have a condition that is socially stigmatized. They report personal experiences of stigma (Jahoda \& Markova, 2004), and may suffer a loss of self-esteem. Also illustrating the discrimination faced by individuals with ID is the use of segregated day services and workshops instead of community-based services 


\section{Stigma in the Social Life among Mothers Having Children with Intellectual Disabilities: Challenges and Suggestions}

(Siperstein, Parker, Noris, \& Widaman, 2011), and the inadequate amount of occupation and choice making opportunities made accessible to individuals with ID (Wehmeyer\& Bolding, 1999). Stigma has been cited as one of the potential barriers to the delivery of adequate services to this population (Gill, Kroese, \& Rose, 2002), resulting in poorer treatment, rejection, and devalued roles within society (Corrigan, Markowitz, Watson, Rowan, \& Kubiak., 2003).. Moreover, discriminatory behaviors lead to the lack of inclusion and social acceptance of persons with ID within local communities as well as the broader society (Jahoda \& Markova, 2004).

Many individuals with moderate to mild ID are indeed aware of the stigma associated with their disability (Jahoda, Wilson, Stalker, \& Cairney, 2010). These individuals experience the stigma of their social identity through their interactions with others, and this experience is often an emotionally painful one (Beart, Hardy, \& Buchan, 2005). Some individuals may even attempt to hide their disability as a way of avoiding stigmatization (Jahoda \& Markova, 2004). Further, regardless of level of awareness, individuals may nevertheless still be prone to negative stigmatic treatment and its consequences (Cooney, Jahoda, Gumley, \& Knott, 2006).

\section{Stigma and parents with ID children}

Most studies conducted looking at family stigma and intellectual disabilities have been qualitative in nature. Based on focus groups and in depth interviews, family members and caregivers reported their experiences of stigma based on their association with the stigmatized individual (Edwardraj, Mumtaj, Prasad, Kuruvilla, \& Jacob, 2010). Other studies have found an association between experiences of stigma and experiences of sorrow among parents of persons with ID (Mak \& Cheung, 2008; Shin \& Nhan, 2009). Given the influence of stigma on the lives of individuals with ID and their families, it is clear that there is a need to advance this body of knowledge and to develop focused interventions to reduce stigma's negative impact as the stigma might place unfair restrictions on the social life of these individuals and their primary caregivers (Green, Davis, Karshmer, Marsh, \& Straight, 2005). Mothers are often in the role of primary caregivers for individuals with intellectual disabilities. However, few studies have looked at the experiences of stigma in mothers having child with intellectual disabilities. Perceived Stigmatized experiences are associated with the feelings of hardship, psychological suffering, sleep disturbances, relationship disturbances, poor quality of life and low self-esteem.

In view of the stated facts and review of literature the present study was planned to explore association between stigma and restrictions in social life of mothers in terms of social relationship, activity and interest. 


\section{Stigma in the Social Life among Mothers Having Children with Intellectual Disabilities: Challenges and Suggestions}

\section{Objectives:}

In view of gaps in this area of research, this study was designed to address the following objectives:

1. To examine the role of functional limitations of children with intellectual disability in restriction in social life among parents of children with intellectual disability.

2. To examine the role of perceived stigma in restriction in the social life of the parents of children with intellectual disability.

\section{Hypotheses:}

In the light of the findings of previous studies and theoretical background, the following hypotheses were formulated.

H1. Severity of the child's disability (functional limitation) would be positively correlated with restriction in social life among the parents of children with intellectual disability.

H2. Perceived stigma would be positively correlated with restriction in social life among the parents of children with intellectual disability.

\section{METHOD}

Design: The present study based on correlational design. In this study the severity of the child's disability (functional limitation) and perceived stigma were tapped as the predictor and restriction in social life was measured as the criterion variable.

Sample: The sample of the study consisted of 51 mothers with intellectually disabled children of varying degree, aged between 3 and 15 years. The participants were sampled from from Deva Integrated Society for Child Care (DISCC) Kamchchha, Indian Institute of Cerebral Palsy and Handicapped Children, Kamala Nagar, Sigra, and Integrated Institute for Disables (IID) Karaundi, Varanasi. Age range of the mothers was between 25 to 55 years. The purposive sampling technique was used in collecting the data. Parents, who met the inclusion and exclusion criteria specified below, were selected.

Inclusion criteria: The inclusion criteria included parents having a child diagnosed with I.D according to DSM IV-TR (2000) criteria their informed consent to participate in the study and who could understand and speak Hindi.

Exclusion criteria: Parents having children with I.D with behavior problems or any neurological conditions, any physical disability, parent who have past or current psychiatric or chronic physical illness and not willing to participate in the study were excluded.

Tools: The following tools were used in the present study.

Personal care Assessment Form (PCAF) -It is a 12 item tool related to the child's capacity to complete activities of daily living (ADL). It was developed by Phillips et.al (1997). The ADL questions on the PCAF inquire about the child with the disability's need for assistance over the past seven days in several different areas (e.g., bed mobility, eating, transfers, toilet use, personal hygiene, bathing, and continence) using a six point scale 
Stigma in the Social Life among Mothers Having Children with Intellectual Disabilities: Challenges and Suggestions

ranging from total independence to total dependence. Higher scores on the PCAF-ADL indicate less ability to perform ADLs independently and, therefore, more functional impairment. Initial investigations of the PCAF-ADL have shown high internal consistency $(\alpha=.94)$.

Perceived Stigma Scale-Perceived stigma was assessed with Perceived Stigma Scale. This scale has been developed during research period. It consists of 10 items divided into two domains: avoidance stigma and associative stigma. It is a 5-point type scale, ranging from 0 = 'never' to $4=$ 'nearly always'. Item scores are added up to give a total score ranging from 0 to 40 , with higher scores indicating high level of perceived stigma.The internal consistency reliability (Cronbach's alpha) of the scale is 0.72 .

Restriction of Social Life Scale -This scale was developed during this research. It has 11items and it assesses the degree to which the stigma of having children with intellectual disabilities limits the social experiences of parents/family members. It provides scores for caregivers' social activities, social interest and limited and reduced social life. Items are rated on a 5-point Likert type scale ranging from 0 (never) to 4 (nearly always).The scores on this scale range from 0 to 44 . The internal consistency reliability of the scale is 0.70 .

\section{Procedure}

Subjects fulfilling the inclusion criteria were selected for the study. A written informed consent was taken from them and the objectives and the procedures of the study were explained in detail. The participants for the present study were contacted individually or in small groups consisting of 2 to 3 parents. Self-administered questionnaires were used to gather the data. All participants were requested to ensure that they have responded to each items of every scale. Participants were told that their anonymity and confidentiality will be maintained.

\section{RESULTS}

To ascertain the relationship, severity of children disability with restriction of social life among the parents of children with intellectual disability bi-variate correlation coefficients were computed. The obtained results are displayed in Table 1 and 2.

Table 1: Coefficients of correlation for child's severity with Social life restrictions of parents of children ID

\begin{tabular}{|lr|c|c|c|c|}
\hline Variables & $\begin{array}{c}\text { Social } \\
\text { Activity }\end{array}$ & $\begin{array}{c}\text { Social } \\
\text { interest }\end{array}$ & $\begin{array}{c}\text { Social } \\
\text { restrictions }\end{array}$ & $\begin{array}{c}\text { Overall } \\
\text { RSL }\end{array}$ \\
\hline $\begin{array}{l}\text { Child's disability } \\
\text { severity } \\
\text { limitation) }\end{array}$ & \begin{tabular}{c} 
(Functional \\
\hline
\end{tabular} & .174 & .022 & $635^{* *}$ & $\mathbf{6 0 9}^{* *}$ \\
\hline
\end{tabular}

** $\mathrm{p}<.01$ level 


\section{Stigma in the Social Life among Mothers Having Children with Intellectual Disabilities: Challenges and Suggestions}

Table 1 shows that child's functional limitation was significantly positively correlated with social restrictions aspect $(\mathrm{r}=.635, \mathrm{p}<.01)$ and overall restriction in social life $(\mathrm{r}=.609$, $\mathrm{p}<.01$ ). Child's functional limitation was also positively associated with other aspects of restriction in social life, social activities and social interest but not significantly.

Table 2: Coefficients of correlation for perceivedstigma with social life restrictions of parents of children ID

\begin{tabular}{|l|c|c|c|c|}
\hline Variables & $\begin{array}{c}\text { Social } \\
\text { activity }\end{array}$ & $\begin{array}{c}\text { Social } \\
\text { interest }\end{array}$ & $\begin{array}{c}\text { Social } \\
\text { restrictions }\end{array}$ & $\begin{array}{c}\text { Overall } \\
\text { RSL }\end{array}$ \\
\hline $\begin{array}{l}\text { Avoidance } \\
\text { stigma }\end{array}$ & .215 & -.232 & $.385^{* *}$ & $.317^{*}$ \\
\hline $\begin{array}{l}\text { Associative } \\
\text { stigma }\end{array}$ & .222 & .102 & $.892^{* *}$ & $.873^{* *}$ \\
\hline Overall stigma & .256 & .026 & $.897^{* *}$ & $.861^{* *}$ \\
\hline
\end{tabular}

$* * \mathrm{p}<.01$ level ; * $\mathrm{p}<.05$ level

Table-2 shows that avoidance stigma was significantly positively correlated with social restriction aspect $(\mathrm{r}=.385, \mathrm{p}<.01)$ and overall restriction in social life $(\mathrm{r}=.317, \mathrm{p}<.05)$. Associative stigma was significantly positively correlated with social restriction aspect ( $\mathrm{r}=.892$, $\mathrm{p}<.01)$ and overall restriction in social life $(\mathrm{r}=.873, \mathrm{p}<.01)$ and overallperceived stigma was also significantly positively correlated with social restrictions $(r=.897, \mathrm{p}<.01)$ and overall restriction in social life $(r=.861, \mathrm{p}<.01)$. However, all dimensions of perceived stigma were positively associated with over all aspects of restriction in social life except social interest, being negative relationship.

\section{DISCUSSION}

This study examined the relationships between child's severity, stigma and restriction in the social life of mothers having girl children with Intellectual Disabilities. Some significant relationships between stigma, child's severity and restriction in social life were found. The first hypothesis was that severity of the child's disability (functional limitation) would be positively correlated with restriction in social life among the parents of children with intellectual disability. The severity of the child's disability positively correlated with social restrictions and overall restriction in social life significantly but not with social activity and social interest. This finding suggests that when severity of child disability increases, their mother's social interest, social activity and social life are restricted. They don't have time to participate in social activities, social gatherings and so on. Their entire effort is only directed for their child care, especially if the child is a girl. Because the norm of our society is different for girls, they are expected much more sincere behavior than boys. Their physical and psychological demands are different. So the 


\section{Stigma in the Social Life among Mothers Having Children with Intellectual Disabilities: Challenges and Suggestions}

caring of disabled girl children puts more physical and mental burden on mothers. It restricts the mother's life socially, mentally and physically. The first hypothesis is, therefore, confirmed. The findings of the present study extend empirical support to Hong, Jin, Nguyen \& Lawrence (2012) who reported direct relationship between intellectual disabilities and caregivers' social functioning.

The second hypothesis was that perceived stigma would be positively correlated with restriction in social life among the parents of children with intellectual disability. In the case of stigma it was found that avoidance stigma positively correlated with social restriction and overall restriction in social life significantly and but not significantly with social activity. It was also found that avoidance stigma negatively correlated with social interest. This suggests that when mothers have feelings of avoidance with society, their social life is restricted in many ways, they find it difficult to maintain their social relationships. They feel annoyed and embarrassed in social situation due to their children's activities. They fail to participate in social activities. But negative correlation with social interest suggests that they might be interested to participate in activities like music, dance, games, and other cultural activities. Such activities may be helpful in refreshing their lives.

Associative stigma was positively and significantly correlated with social restrictions and overall restriction in social life and non-significantly with social activities and social interest dimension. This finding suggests that when members of society do not want to maintain their relationship with mothers and their children they totally feel restriction in their social life, which consequently affects their personal, emotional and physical life. The overall stigma was positively and significantly correlated with social restrictions and overall restriction in social life and non-significantly with social activities and social interest dimension of restriction. Therefore, second hypothesis was confirmed. This is in accordance with the results of Mak \& Cheung (2008), who reported that stigma is expressed in parent caregivers via restrictions in key social interactions.

\section{CONCLUSION}

The findings expand our knowledge concerning how intellectual disabilities limit parents' social functioning and illuminates a critical domain that adversely impacts caregivers 'social and psychological experiences. So, it is concluded that child's functioning status and parental perceived stigma are the important factors that determine the caregivers' social functioning. It needs to be addressed properly.

\section{IMPLICATIONS}

The findings of the study are important for the implementation of anti-stigma interventions, which might address the specific social domains in which caregivers are affected. The intervention programmes (such as community counselling and parent training) may help caregivers to cope with the various forms of interpersonal discrimination encountered in their 


\section{Stigma in the Social Life among Mothers Having Children with Intellectual Disabilities: Challenges and Suggestions}

lives. Such cognitive-behavioral intervention techniques and psycho-educational approaches may also encourage caregivers to break patterns of secrecy and withdrawal by confiding in trusted family members. Such an assumption is getting empirical support from the results of the present study. It is expected that this study will spur future researchers to examine the mechanisms underlying the stigma of intellectual disabilities and interventions to reduce their impact on caregivers' social functioning and thus making their social lives more comfortable and happier.

\section{REFERENCES}

Abraham, C., Gregory, N., Wolf, L. \& Pemberton, R. (2002).Self-esteem, stigma and community participation amongst people with learning difficulties living in the community. Journal of Community and Applied Social Psychology, 12, 430-443.

Amcin (2010).Families of the mentally retarded challenges and concerns. Accessed 2015.12.28 at http://www.amcin.org

Beart, S., Gillian Hardy, G. \& Buchan, L. (2005). How People with Intellectual Disabilities View Their Social Identity: A Review of the Literature. Journal of Applied Research in Intellectual Disabilities, 18, 47-56.

Cooney, G., Jahoda, A., Gumley, A., \& Knott, F. (2006). Young people with intellectual disabilities attending mainstream and segregated schooling: Perceived stigma, social comparison and future aspirations. Journal of Intellectual Disability Research, 50, 432444.

Corrigan, P. W. (2000). Mental health stigma as social attribution: Implications for research methods and attitude change. Clinical Psychology Science Practice, 7, 48-67.

Corrigan, P., \& Watson, A. M. (2002).Understanding the impact of stigma on people with mental illness. World Psychiatry, 1, 16-20.

Corrigan, P., Markowitz, F. E., Watson, A., Rowan, D., \& Kubiak, M. A. (2003).An attribution model of public discrimination towards persons with mental illness. Journal of Health and Social Behavior, 44, 162-179

Edwardraj, S., Mumtaj, K., Prasad, J. H., Kuruvilla, A., \& Jacob, K. S. (2010). Perceptions about intellectual disability: A qualitative study from Vellore, South India. Journal of Intellectual Disability Research, 54, 736-748.

Gill, F., Kroese, B. S., \& Rose, J. (2002). General practitioners' attitudes to patients who have learning disabilities. Psychological Medicine, 32, 1445-1455.

Goffman, E. (1963). Stigma: Notes on the Management of Spoiled Identity. New York: Touchstone.

Green, S., Davis, C., Karshmer, E., Marsh, P., \& Straight, B. (2005) Living stigma: the impact of labeling, stereotyping, separation, status loss, and discrimination in the lives of individuals with disabilities and their families. Sociological Inquiry, 75,197-215.

Hong, N., Jin, Y. S., Nguyen, V. N., \&Lawrence, H. Y. (2012).Stigma and restriction on the social life of families of children with intellectual disabilities in Vietnam. Singapore M J, 53 (7), 451-457

Jahoda, A., \& Markova, I. (2004).Coping with social stigma: People with intellectual disabilities moving from institutions and family home. Journal of Intellectual Disabilities Research, 48, 719-729. 


\section{Stigma in the Social Life among Mothers Having Children with Intellectual Disabilities: Challenges and Suggestions}

Jahoda, A., Wilson, A., Stalker, K., \& Cairney, A. (2010).Living with stigma and selfperceptions of people with mild intellectual disabilities. Journal of Social Issues, 66, 521534.

Mak, W. W. \& Cheung, R. Y. M. (2008). Affiliate Stigma Among Caregivers of People with Intellectual Disability or Mental Illness. Journal of Applied Research inIntellectual Disabilities, 21 (6), 532-545.

Östman, M. \& Kjellin, L. (2002) Stigma by association: psychological factors in relatives of people with mental illness. British Journal of Psychiatry, 181, 494-498.

Phelan, J., Bromet, E. J., \& Link, B. G. (1998).Psychiatric illness and family stigma. Schizophrenia Bulletin, 24, 115-126.

Phillips, C. D., Hawes, C., Fournier, C., Elliott, T., Dyer, J., Naiser, E. J., Patnaik, A. \& Kimbell, A. M. (2009). Personal care assessment form (pcaf) user's manual. Texas A\&M Health Science Center School Of Rural Public Health.

Pratt, H. D. (2010). Psychological issues in chronically ill adolescents. In H. Omar, D. E. Greydanus, D. R. Patel, \& J. Merrick (Eds.), Adolescence and chronic illness: A public health concern (pp. 151-164). New York: Nova Science Publishers.

Sartorius, N. (1999). One of the last obstacles to better mental health care: the stigma of mental illness. In: Guimon, J., Fischer, W., \& Sartorius, N., editors. The Image of Madness: The Public Facing Mental Illness and Psychiatric Treatment. Basel, Switzerland: Karger.

Schalock RL, Luckasson RA, Shogren K.A., (2007). The renaming of mental retardation: understanding the change to the term intellectual disability. Intellectual and Developmental Disabilities, 45, 116-124.

Shin, J. Y., \&Nhan, N. V. (2009). Predictors of parenting stress among Vietnamese mothers of young children with and without cognitive delay. Journal of Intellectual \& Developmental Disability, 34, 1-10.

Siperstein, G. N., Parker, R. C., Noris, J., \& Widaman, K. F. (2011).A national study of Chinese youths' attitudes toward students with intellectual disabilities. Journal of Intellectual Disability Research published online, doi: 10.1111/j.1365-2788.2011.01382.

Struening, E. L., Perlick, D. A., Link, B. G., Hellman, F., Herman, J. D., \&Sirey, J. A. (2001). The extent to which caregivers believe most people devalue consumers and their families. Psychiatric Services, 52, $1633-1638$.

Wehmeyer, M. L., \& Bolding, N. (1999). Self-determination across living and working environments: A matched-samples study of adults with mental retardation. Mental Retardation, 37, 353-363.

World Health Organization (WHO)(2007).Atlas: global resources for persons with intellectual disabilities. Geneva. World Health Organization.

World Health Organization (1992)International Classification of Diseases-Tenth Revision. Geneva. World Health Organization.

How to cite this article: R Mourya, R Singh, A Rai (2016), Stigma in the Social Life among
Mothers Having Children with Intellectual Disabilities: Challenges and Suggestions,
International Journal of Indian Psychology, Volume 3, Issue 3, No. 11, DIP:
18.01.198/20160303, ISBN: 978-1-365-21307-6

